\title{
The Health Outcome Assessment of Healthcare Workers Engaged in SARS-CoV2 Pandemic Services: A Survey-Based Study
}

\author{
Suraiya Khanam Ansari ${ }^{1}$, Prashant Tripathi ${ }^{2}$ \\ ${ }^{1}$ Assistant Professor, Department of Microbiology, GSVM Medical College, Kanpur, U.P, India \\ ${ }^{2}$ Associate Professor, Department of Biochemistry, GSVM Medical College, Kanpur, U.P, India
}

Corresponding Author: Prashant Tripathi

\begin{abstract}
Background: The COVID-19 pandemic adversely hit India and its economy recently and is associated with the increasing uncertainty among the mental health status of health care workers. When the World Health Organization focus has mostly on testing and finding a vaccine, healthcare workers are passing with a myriad of mental health problems. The present study decided to conduct an online survey for assessing health status.
\end{abstract}

Aims and Objective: To assess the health of healthcare workers engaged in SARS-CoV-2 duties.

Methods: From 4th July 2020 to 4th October 2020 an online Google Form, a survey was conducted among healthcare workers. The survey collected data on socio-demographic and health variables especially during COVID-19 duties in the form of questionnaires.

Results: There were a total of 196 responses from different provinces of India collected. The mean age of the respondents was around 41 years with $62.3 \%$ males and $37.7 \%$ females. The study showed that most HCWs showed a change in the sleeping habit.

Conclusions: The present study concluded that there is a need for holistic interventions among health care workers and more systematic and longitudinal evaluations of mental health status further needed.

Keywords: SARS-CoV-2; Health; Health care workers; COVID-19; Mental Health; Stress

\section{INTRODUCTION}

Severe acute respiratory syndrome coronavirus-2 (SARS-CoV-2) is a respiratory associated pandemic as declared by the World Health Organization (WHO) on 11 March $2020^{1}$. International Committee on Taxonomy of Viruses has made nomenclature of 2019-nCov as severe acute respiratory syndrome coronavirus- 2 (SARS-CoV-2) ${ }^{2}$. In this global pandemic of SARS-CoV-2, healthcare workers (HCWs) faced physical and psychological stress. While giving care to patients the HCWs are generally at high risk of infection exposure through either patient's environment or biological samples at laboratories ${ }^{3-4}$. Such stress may have some negative effects on their health. HCWs exposed to SARS infection and undergone psychological stress as reported by some authors ${ }^{5-6}$. Such consequences of stress may last long after the outbreak that may turn into depression and posttraumatic stress disorder ${ }^{7}$.

Healthcare workers (HCWs) are the most understudied segment of the population during SARS- CoV-2 and experienced risk of developing infection due to close contact either with the infected patients or with the laboratory samples ${ }^{8}$. However, some authors including Centers for Disease Control and Prevention (CDC) have reported the plight of HCWs and found $55 \%$ HCWs were infected during COVID$19^{9-11}$. In one of the studies conducted in US HCWs, it was found that due to 
underreporting of infection in HCWs population, $84 \%$ population devoid of HCWs information ${ }^{12}$. In one of the previously published, it was found that 127\% HCWs population suffered from MERS CoV infection ${ }^{13}$. Several published literatures showed the psychological impact of MERS-CoV infection of HCWs health outcome ${ }^{14-17}$.

\section{MATERIAL AND METHODS Study Design}

This cross-sectional study conducted among the healthcare workers of Indian Hospitals and Medical Colleges. The study was pre-approved by the Institutional Ethics Committee (IEC), GSVM Medical College, Kanpur for the final permission. After obtaining the permission of IEC the study was conducted. The study carried out for 60 days, from 4th July 2020 to 4th September 2020. The participants aged between 20 and 54 years old participated in the present study. The questionnaire was developed following the previously published literature and framed by author ${ }^{18}$. The participants were requested to give online consent before filling the questionnaire using Google Forms. Telephonic communication with participants if needed was done time to time during the study period. The questionnaire consisted of information related to perturbations in mental health status, physical workout, sleeping and meals patterns. The complete Google form consisted of 26 items along with socioeconomic and demographic information. Data collected through online mode was kept confidential and those participants who did not give their consent or did not answer the questions were excluded from the present study. Participants were given liberty to quit from the survey at any point in time.

The first section of the questionnaire consists of post demographic information consists of 10 questions that explored the healthcare workers stressful event and emotions. Each question rated on a 6 points scale $(0=$ not experienced; $1=$ very rarely experienced; $2=$ rarely experienced; $3=$ sometimes experienced; $4=$ often experienced and $5=$ very often experienced). The questions focused on $r$ the change in sleep, diet and physical activity pattern due to COVID engagements.

\section{Sample size}

The minimum sample size to perform this cross-sectional study was calculated using equation (Eqn 1) 1.

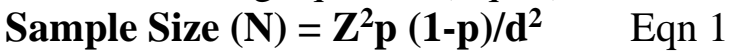
Where $Z^{2}$ is the normal variate at $5 \%$ type 1 error $(\mathrm{P}<0.05)$ is $1.96, \mathrm{p}=0.15$ and $\mathrm{d}=0.05$ $1-\alpha / 2$

The sample size used in the present study is 196

\section{Study variables}

Socio demographic characteristics were gender, age, educational status, marital status, employment status was considered as explanatory/independent variables. Whereas the mental health status, physical exercise, sleeping and meals patterns were considered as dependent variables.

\section{Data analysis}

The data imported on Microsoft Excel file format and analyzed for the percentage by circular statistical graphic that was presented in the Google Forms result section.

\section{RESULT}

A total of 196 healthcare workers from all provinces of India responded to the questionnaire, no one is excluded from the study as all have given complete information. Among 196 respondents, $62.3 \%$ were males and $37.7 \%$ were females. Participants with an undergraduate degree (44.2\%) made up the largest study group followed by professionals (35\%). Postgraduate (18.2\%) and Intermediate or below (2.6\%). Out of total HCWs, nurses were $59.70 \%$ followed by others including COVID-19 testing laboratory staffs (35.1\%) and doctors (5.2\%). Variable characteristics 
of the present study are mentioned in Table 1. In the present study, the maximum number of participants (32.5\%) falls in the category that they are doing work for 8-10 within 24 hours. In the present study, it was found that COVID-19 work made HCWs engage in other activities including social and family work. The proportion of HCWs population (22.1\%) presented very often and often $(22.1 \%)$, they are getting time to do other things due to COVID-19 wok assignments. The sleeping pattern of $53.2 \%$ HCWs was also found to be changed due to COVID-19 work. In the present study, 15.6\% HCWs population were told that they felt distant from their own emotions very often and often (14.3\%) whilst the majority falls in the sometimes category (27.3\%).

Table 1: Variable characteristics of health care workers

\begin{tabular}{|l|l|}
\hline Variables & Response Percentage (\%) \\
\hline Gender & 62.3 \\
\hline Male & 37.7 \\
\hline Female & 44.2 \\
\hline Education & 35.0 \\
\hline Undergraduate & 18.2 \\
\hline Professionals & 2.6 \\
\hline Postgraduate & 59.70 \\
\hline Intermediate or below & 35.10 \\
\hline Occupation & 5.20 \\
\hline Nurses
\end{tabular}

\section{DISCUSSION}

The present study suggests that $59.2 \%$ of primary healthcare workers (Physicians) were involved actively in COVID-19 duty with $44.2 \%$ with undergraduate qualifications. It was found in the present study that $32.5 \%$ of HCWs have worked between 8-10 hours in management of the COVID-19 pandemic. This continuous duty hour of the HCWs restricted to perform other physical activities because they didn't spare time for the physical activities and pushed them to a slight sedentary lifestyle, which is the most important cause for metabolic disorders. In one of the recent studies, it was found that a sedentary lifestyle is posing health risk ${ }^{19}$. The result of the present study revealed that $28.6 \%$ of HCWs were suffered chronic difficulty in sleeping, while $23.4 \%$ showed moderate sleeping difficulty. A recent study published by Harvard showed that disturbance in sleeping can result in both mental and physical health problems ${ }^{20}$. Chronic insomnia can lead to a variety of health problems including diabetes, cardiovascular diseases and hypertension ${ }^{20}$. The result also showed that sleeping habit or time of sleeping changed in 53.2\% HCWs. The result of the present study showed that 22.1\% HCWs felt loneliness as they didn't get time to engage in other familiar activities. In the present study, $44.20 \%$ HCWs found that their hour's spending in physical exercise decreased due to COVID19 management, while $36.40 \%$ responded no change in exercise hours.

\section{CONCLUSION}

To conclude, the presentation highlighted that the HCWs who played an important role to fight against this worldwide pandemic placed their physical and mental health on risk. This study will help the government bodies and local administration to frame effective guidelines for HCWs health management and monitoring.

\section{ACKNOWLEDGEMENT}

The authors are thankful to Multidisciplinary Research Unit, MoHFW, GSVM Medical College Kanpur for providing the facilities for doing research work. The authors are also thankful to Dr. Alok Raghav, Scientist-C, Multidisciplinary Research Unit, MoHFW, GSVM Medical College Kanpur for doing analysis.

\section{Conflict of Interest: None}

\section{Source of Funding: None}

\section{Ethical Approval: Approved}

\section{REFERENCES}

1. World Health Organization. Coronavirus (COVID-19) https://experience.arcgis.com/experience/6 85d0ace521648f8a5beeeee1b9125cd.

[Accessed 4 April 2020]. 
2. Gorbalenya AE, Baker SC, Baric RS, de Groot RJ, Drosten C, Gulyaeva AA, et al. Severe acute respiratory syndrome-related coronavirus: the species and its viruses-a statement of the Coronavirus Study Group. bioRxiv 2020 Feb 11.doi:10.1101/2020.02.07.937862

3. C. Hammen. Risk factors for depression: an autobiographical review. Annu Rev Clin Psychol, 14 (2018), pp. 1-28, 10.1146/annurev-clinpsy-050817-084811.

4. D. Koh, M.K. Lim, S.E. Chia, S.M. Ko, F. Qian, V. Ng, et al. Risk perception and impact of severe acute respiratory syndrome (SARS) on work and personal lives of healthcare workers in Singapore: what can we learn?Med Care, 43 (7) ,2005, pp. 676-682.

5. A.O. Chan, C.Y. Huak. Psychological impact of the 2003 severe acute respiratory syndrome outbreak on health care workers in a medium size regional general hospital in Singapore. Occup Med (Lond), 54 ,2004, pp. 190-196.

6. J. Brug, A.R. Aro, A. Oenema, O. de Zwart, J.H. Richardus, G.D. Bishop. SARS risk perception, knowledge, precautions, and information sources, the Netherlands. Emerg Infect Dis, 10 (8) ,2004, pp. 1486-1489, 10.3201/eid1008.040283.

7. J.I. Bisson, B. Tavakoly, A.B. Witteveen, D. Ajdukovic, L. Jehel, V.J. Johansen, et al.TENTS guidelines: development of postdisaster psychosocial care guidelines through a Delphi process. Br J Psychiatry, $196 \quad$ (1),2010,, pp. 69-74, 10.1192/bjp.bp.109.066266.

8. Wang $\mathrm{X}$, Zhang $\mathrm{X}, \mathrm{He}$ J. Challenges to the system of reserve medical supplies for public health emergencies: reflections on the outbreak of the severe acute respiratory syndrome coronavirus 2 (SARS-CoV-2) epidemic in China. Biosci Trends. 2020,14(1):3-8.

9. Gao W, Sanna M, Wen CP . Geo temporal distribution of 1,688 Chinese healthcare workers infected with COVID-19 in severe conditions, a secondary data analysis. medRxiv. 2020:2020.2003.2019.20032532.
10. Kluytmans M, Buiting A, Pas S, et al. SARS-CoV-2 infection in 86 healthcare workers in two Dutch hospitals in March 2020. medRxiv. 2020:2020.2003.2023.20041913.

11. Ran L, Chen X, Wang Y, Wu W, Zhang L, Tan X. Risk Factors of Healthcare Workers With Coronavirus Disease 2019: A Retrospective Cohort Study in a Designated Hospital of Wuhan in China. Clin Infect Dis. 2020 ,71(16):2218-2221. doi: $10.1093 /$ cid/ciaa287.

12. CDC COVID-19 Response Team. Characteristics of Health Care Personnel with COVID- 19 - United States, February 12-April 9, 2020. MMWR Morb Mortal Wkly Rep. 2020, (69):477-481.

13. Hunter JC, Nguyen D, Aden B, Al Bandar Z, Al Dhaheri W, Abu Elkheir K, et al. Transmission of Middle East respiratory syndrome coronavirus infections in healthcare settings, Abu Dhabi. Emerg Infect Dis 2016, 22:647-56.

14. Alsubaie S, Hani Temsah M, Al-Eyadhy AA, Gossady I, Hasan GM, Al-rabiaah A, et al. Middle East respiratory syndrome coronavirus epidemic impact on healthcare workers' risk perceptions, work and personal lives. $\mathrm{J}$ Infect Dev Ctries 2019;13:920-6.

15. Abolfotouh MA, AlQarni AA, Al-Ghamdi SM, Salam M, Al-Assiri MH, Balkhy HH. An assessment of the level of concern among hospital-based health-care workers regarding MERS outbreaks in Saudi Arabia. BMC Infect Dis 2017, 17(4):1-10.

16. Khalid I, Khalid TJ, Qabajah MR, Barnard AG, Qushmaq IA. Healthcare workers emotions, perceived stressors and coping strategies during a MERS-CoV outbreak. Clin Med Res 2016, 14(1):7-14.

17. Al-Rabiaah A, Temsah MH, Al-Eyadhy AA, Hasan GM, Al-Zamil F, Al-Subaie S, et al. Middle East Respiratory SyndromeCorona Virus (MERS-CoV) associated stress among medical students at a university teaching hospital in Saudi Arabia. J Infect Public Health 2020, 13(5):687-91.

18. Amal M.Qasem Surrati, Farah M.Asad Mansuri, Abeer A.Ayadh Alihabi. Psychological impact of the COVID-19 
pandemic on health care workers. Journal of Taibah University Medical Sciences. 15;6, 2020, 536-543.

19. Park JH, Moon JH, Kim HJ, Kong MH, Oh YH. Sedentary Lifestyle: Overview of Updated Evidence of Potential Health Risks. Korean J Fam Med. 2020,41(6): 365- 373.

20. https://news.harvard.edu/gazette/story/202 0/04/sleep-problems-becoming-risk- factor-as- pandemic-continues/. Accessed on $11 / \mathrm{Feb} / 2021$.

How to cite this article: Ansari SK, Tripathi P. The health outcome assessment of healthcare workers engaged in SARS-CoV2 pandemic services: A survey-based study. International Journal of Research and Review. 2021; 8(12): 724-728. DOI: https://doi.org/10.52403/ijrr. 20211288 